\title{
Thermostability, photostability, and toxicity of clove oil nanoparticles against Cryptolestes ferrugineus (Stephens) (Coleoptera: Laemophloeidae)
}

\author{
SILVI IKAWATI ${ }^{1,2, \bullet}$, TOTO HIMAWAN ${ }^{2}$, ABDUL LATIEF ABADI ${ }^{2}$, HAGUS TARNO $^{2}$ \\ ${ }^{1}$ Graduate Program, Faculty of Agriculture, Universitas Brawijaya. Jl. Veteran, Malang 65145, East Java, Indonesia. \\ Tel.: +62-341-551665, 565845, Fax.: +62-341-560011, •email: silviikawati@ub.ac.id \\ ${ }^{2}$ Department of Plant Pest and Disease, Faculty of Agriculture, Universitas Brawijaya. Jl. Veteran, Malang 65145, East Java, Indonesia
}

Manuscript received: 4 September 2020. Revision accepted: 23 September 2020.

\begin{abstract}
Ikawati S, Himawan T, Abadi AL, Tarno H. 2020. Thermostability, photostability, and toxicity of clove oil nanoparticles against Cryptolestes ferrugineus (Stephens) (Coleoptera: Laemophloeidae). Biodiversitas 21: 4764-4771. Problems related to the essential oils as insecticides are their volatility, poor solubility in water and environmental degradation (such as caused by high temperatures and UV light) which can adversely affect the application. An ideal botanical insecticide formulation would maintain the level of the main compounds adequate for pest control. This study was to evaluate the stability of polyethylene glycol (PEG) coated nanoparticles loaded with clove (Syzygium aromaticum) essential oil to high temperature and UV light also their toxicity to $C$. ferrugineus. There is a reduction in nanoparticle size after heating from 257 to $173 \mathrm{~nm}$ and there is no difference in size distribution. After heating and UV-light treatment, eugenol content in free clove oil decreased significantly, while on nanoparticles there were not significantly changed, that indicated greater stability on the nanoformulation. The median lethal concentration (LC50) of CO-NPs to $C$. ferrugineus adults value for 72 and 120 hours was 0.734 and $0.676 \%$.
\end{abstract}

Keywords: Botanical insecticide, Cryptolestes ferrugineus, nanoformulation, photostability, thermostability

\section{INTRODUCTION}

The Rusty grain beetle, Cryptolestes ferrugineus (Steph.) is one of the destructive pests of stored grain and has wide dissemination. This insect pest is widespread in temperate and tropical regions and the wet and dry zones. Cryptolestes insects are a secondary pest, which benefits from grains previously damaged. A frequently used control method against storage pests is a synthetic insecticide application (Gasch 2014).

Phosphine and methyl bromide are the two widely used pesticides that are processed worldwide for product protection. Controlling insect pests using synthetic molecules and oil derivatives constantly have produced secondary effects (toxicity mammalian, insect resistance, and ecological hazards). The recent phase-out of the ozonedepleter methyl bromide has left phosphine as the only viable fumigant for the industry for routine disinfestation of stored commodities. The development of resistance to phosphine in $C$. ferrugineus has occurred (Nayak et al 2013). Alternatives are required to traditional fumigants and contact insecticides since many are banned from the market. The use of botanical insecticides that are more environmentally friendly than synthetic chemicals is considered as an alternative method.

Among botanical extracts used as insecticides, essential oils are a promising alternative because of their worldwide availability and relative cost-effectiveness (Campolo et al. 2018). Plant essential oils are volatile substances mixture composite mainly by terpenoids and used for their aromatic qualities. There are a variety of insecticides that have toxicological properties, deterrents, and repellents for the control in stored products, one of them is clove (Syzygium aromaticum) essential oil (Plata-Rueda et al. 2018). The essential oil from clove has several bioactive compounds. The main compound of clove oil was 2-methoxy-4-(2propenyl)-phenol or eugenol and trans-caryophyllene (Ikawati et al. 2020).

Botanical insecticides have favorable eco-toxicological properties (low human toxicity, rapid degradation, and reduced environmental impact), making them ideal for organic farming (Zanuncio et al. 2016). Even with its promising properties, essential oils as pesticides have some disadvantages. Problems related to the volatility of the oils, their poor solubility in water solubility, and environmental degradation, related to their chemical structure, which can adversely affect the application. The persistence of the oil, and consequently its protection against pests, is of short duration because of volatility. EOs are hydrophobic and generally lipophilic, their density is often lower than that of water, and they are soluble in organic solvents (Campolo et al. 2018). Typically an agrochemical product is expected to remain stable, short term stability trials at elevated temperatures are needed (Isman 2016). In the Balkan peninsula, the temperature was also found to be the strongest bioclimatic factor affecting the chemical composition of rosemary oil (Lakušić et al. 2012). Because it requires the right formulation form to reduce these disadvantages.

An ideal pesticide formulation would maintain an active ingredient level adequate for pest control but leave minimum environmental residue (Roy et al. 2014). There 
are formulations would not only replace toxic, nondegradable ingredients/adjuvants of the conventional formulations but also increase the bio-efficacy of the products through incorporating the latest technologies including size reduction (Wettable Powder to Suspension Concentrate, Soluble Concentrate to Microemulsion), increased coverage of applied surface area (EC to $\mathrm{ME} /$ Nano-formulations), reduced wastage (Dust/WP to Controlled Release Formulations) and dose rates of applied same pesticides to improve food quality with minimum pesticide residues (Hazra et al. 2017). Using nanotechnology to design and prepare targeted pesticides with an environmentally responsive controlled release via compound and chemical modifications has also shown great potential in creating novel formulations (Huang et al. 2018). A significantly large part of current literature on the encapsulation of essential oils deals with micrometric size capsules, which are used for the protection of the active compounds against environmental factors (e.g., oxygen, light, moisture, and $\mathrm{pH}$ ), to decrease oil volatility and to transform the oil into a powder (Bilia et al. 2014).

There are many methods to produce a nanocapsule/ particle, one of them is the melt-dispersion method to prepare the polyethylene glycol (PEG) coating nanoparticles, a procedure that is very simple and can be easily compared to other nanotechnologies (Yang et al. 2009). Polymers have been widely used in agriculture for applications including the controlled release of pesticides and other active ingredients (Roy et al. 2014). The process of molecular diffusion through polymers and synthetic membranes has been used as an effective and reliable means of attaining not only the controlled release of drugs and pharmacologically active agents but also of pesticides (Bandani et al. 2009). The PEG is a polymer that has good solubility in many organic solvents, low melting point (below $65^{\circ}$ ), low toxicity, ability to dissolve some compounds (Koh et al. 2013). It is predicted that the polyethylene glycol can act as one of the ideal universal carriers for most poorly soluble chemical (Chiou and Riegelman 1971). The objective of this study was to evaluate the stability of clove essential oils polymer-based nanoformulation in high temperature and their toxicity to $C$. ferrugineus.

\section{MATERIALS AND METHODS}

\section{Test insect}

The method for insects rearing followed Ikawati et al. (2020). The C. ferrugineus Indonesia strain adults obtained from the laboratory of entomology, Faculty of Agriculture, University of Brawijaya. Insects reared in glass jars (5 L) containing rice and yeast (ratio 95\%: 5\%). Insects are maintained in laboratory conditions at temperature $27 \pm 2^{\circ} \mathrm{C}$ and relative humidity of $70 \% \pm 5 \%$. Insects reared already for several generations. Adult insects emerging, aged 1-14 days, used to test the contact and fumigant toxicity. All experimental procedures were performed under the same environmental conditions. To avoid contamination, feed sterilization is carried out. Rice was sterilized by cooled at$15^{\circ} \mathrm{C}$ for a week. The rice used was the IR64 variety.

\section{Preparation of clove oil nanoparticles (CO-NPs)}

Clove (Syzygium aromaticum L.) essential oil obtained from essential oil farmer in subdistrict Kesamben district Blitar and PEG 6000 (molecular mass 5000-7000) pro analysis (pa) from Merck (Hohenbrunn, Germany) are the main materials in the preparation of this nanoparticles. Clove oil nanoparticles (CO-NPs) are prepared using the melt dispersion method (Yang et al. 2009) with modification in cooled temperature and sieve size. Some PEG $6000(100 \mathrm{~g})$ was heated to $65^{\circ} \mathrm{C}$. PEG has blended with $10 \mathrm{~g}$ of clove oil after melting. The mixture was stirred for $30 \mathrm{~m}$. The mixture was then cooled naturally at $12^{\circ} \mathrm{C}$ for $12 \mathrm{~h}$, ground in a cooled mortar (refrigerated at $12^{\circ} \mathrm{C}$ ), and sieved using a 230 mesh sieve. The powders were placed in airtight polyethylene pouches and stored in desiccators containing calcium chloride at $27 \pm 2{ }^{\circ} \mathrm{C}$ before further testing.

\section{Thermostability of CO-NPs}

Sample of free clove oil (CO) and $10 \%$ of nanoparticles clove oil (CO-NPs) were stored in a closed glass jar and were placed in an oven (temperature $40 \pm 2{ }^{\circ} \mathrm{C}$ ). The stability of the $\mathrm{CO}$ and CO-NPs to temperature was monitored for 6 weeks. The nanoparticles composition was analyzed before and after storage treatment, and the formulation was considered stable if the average size, size distribution, and composition of nanoparticles did not significantly different.

\section{Size of clove oil nanoparticles}

Samples were determined by Dynamic Light Scattering (DLS) using Malvern Zetasizer Nano S (Malvern Instruments, UK). The DLS instrument was used to determine the average size and size distribution of CO-NPs surface charge at $25^{\circ} \mathrm{C}$. After 2 days of storage, $0.2 \mathrm{~g}$ of clove nanoparticles samples were suspended in $10 \mathrm{~mL}$ of distilled water for $30 \mathrm{~min}$. Then, the dispersion is filtered using Whatman No. 1 filter paper. Each test was carried out in triplicate. The average size and size distribution were recorded before and after the storage process at $40 \pm 2^{\circ} \mathrm{C}$ for six weeks. For PDI results analysis was used approximate values for dispersity parameters (Nobbmann 2014) (Table 1).

Table 1. Approximate values for dispersity parameters of PDI from DLS

\begin{tabular}{ccccc}
\hline \multirow{2}{*}{ Definition } & \multicolumn{3}{c}{ Monodisperse } & \multicolumn{2}{c}{ Polydisperse } \\
\cline { 2 - 5 } & Uniform & Narrow & Moderate & Broad \\
\cline { 2 - 5 } & 0.0 & $0.0-0.1$ & $0.1-0.4$ & $>0.4$ \\
\hline$=(\text { stddev/mean })^{\wedge} 2$ & & &
\end{tabular}




\section{$\mathrm{CO}$ and CO-NPs composition pre-/post-treatment}

The compounds of $\mathrm{CO}$ and $\mathrm{CO}-\mathrm{NPs}$ were analyzed by Gas Chromatography-Mass Spectrometer (GCMS) with GCMS Shimadzu Model QP-2010 Plus Mass Spectrometer equipped with a capillary column (HP-5, $25 \mathrm{~m} \times 0.25 \mathrm{~mm}$, $0.25 \mathrm{~m}$ film thickness). For oil extraction from $10 \% \mathrm{CO}$ $\mathrm{NPs}$, The $0.5 \mathrm{~g}$ of sample was diluted in $5 \mathrm{~mL}$ of distilled water and then heated at $50^{\circ} \mathrm{C}$ for $30 \mathrm{~min}$; then, $4 \mathrm{~mL}$ of absolute ether was added to collect the extracted CO. Mass Spectrometer condition: the carrier gas is helium with a

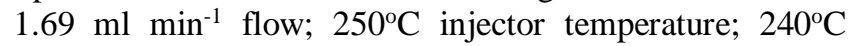
interface temperature; $200^{\circ} \mathrm{C}$ ion source temperature; a temperature of $\mathrm{GC}$ oven is carried out at $50^{\circ} \mathrm{C}$ for 2 minutes, programmed at $5^{\circ} \mathrm{C} \min ^{-1}$ to $200^{\circ} \mathrm{C}$, then held at this temperature for 15 minutes; mass spectrum was recorded at $70 \mathrm{eV}$. Compounds were identified by comparing their retention times with known compounds and also comparing their mass spectra with those stored in Wiley 8 Library (Comparative quality> 80\%). The relative percentage amount is obtained directly from the GC peak region.

\section{Photostability of CO-NPs}

The method for CO-NPs photostability test followed Forim et al. (2013) (Forim et al. 2013). NP was stored for 15 days in a controlled environment. The sample is divided between several glass bottles, which are then sealed. Clove oil was used as a positive control in the same treatment. Samples were incubated in a box irradiated with four UV lamps (Philips $15 \mathrm{~W}$ type actinic lamp; $\mathrm{P}=45.0 \mathrm{~cm}, \mathrm{~L}=$ $2.6 \mathrm{~cm}$; Philips, Netherlands) at a constant temperature of $30 \pm 2^{\circ} \mathrm{C}$. The box was constructed from completely mirrored wood $(\mathrm{P}=60.0 \mathrm{~cm}, \mathrm{H}=40.0 \mathrm{~cm}$, and $\mathrm{L}=60.0$ $\mathrm{cm})$. The UV lamp was placed over the sample at a distance of $25 \mathrm{~cm}$. Samples were stirred daily to maintain uniform exposure to moisture and UV radiation. Samples were analyzed at time intervals (on days 0,5 , and $11 \mathrm{~d}$ ) for GC-MS analysis. For GC-MS conditions described in CO and CO-NPs composition pre-/post-treatment method.

\section{Residual contact toxicity of $\mathrm{CO}$ and CO-NPs}

Samples of $20 \mathrm{~g}$ of rice were prepared with only $\mathrm{CO}$ or $10 \%$ CO-NPs. For CO concentrations, ranging from $0.05 \%$ to $0.25 \%$ and CO-NPs from $0.6 \%$ to $3 \%$ (w/w) (same concentration used to calculate essential oil loading efficiency by Gonzales et al., 2014 for bergamot essential oil was around 78\%) (González et al. 2014). For CO, the rice samples were treated with $3 \mathrm{~mL}$ of the hexane $\mathrm{CO}$ solution and allowed air-dried for 2 hours, before being put in $100 \mathrm{~mL}$ glass containers and sealed. CO-NPs (in solid form) is mixed with rice and vigorously shaken to spread the particles (weakly repeated). Rice samples treated with hexane or PEG 6000 alone were used as controls. Twentyinsects were inserted into a glass container. Samples were stored at $27 \pm 2{ }^{\circ} \mathrm{C}, 60-70 \% \mathrm{RH}$ for 6 weeks. Mortality evaluation was recorded after 72 and $120 \mathrm{~h}$. Death insects were defined as the inability to move when disturbed. Replication is carried out four times.

\begin{abstract}
Statistical analysis
The percentage of corrected mortality was calculated based on the Abbot (1925)(Abbott 1925). Kruskal-Wallis (KW) nonparametric analysis of variance was used to determine the means, using the procedure of SPSS 16. The mortality data at 72 and $120 \mathrm{~h}$. were subjected to probit using the statistical software SPSS 16.0 to get the LC50 and LC90 values. Data analysis of the experimental results of nanoparticles size, PDI (polydispersity index), LC50 and LC90 used paired t-test at the 5\% level.
\end{abstract}

\section{RESULTS AND DISCUSSION}

\section{Thermostability and photostability of CO-NPs}

There are significantly different and reduction in nanoparticle size after heating from 257 to $173 \mathrm{~nm}$ (Table 2). This happens probably due to heat that could cause the melting process of PEG, which may have softened and melted the PEG wall (Yang et al. 2009). The PDI to know a measure of the size distribution of NPs. The results showed that CO-NPs were moderately polydisperse distribution type before and after heating. However, the PDI of CONPs that was heated or stored at $40^{\circ} \mathrm{C}$ was not significantly different than CO-NPs before heated. The size distribution of the nanoparticles stored for 0 weeks and 6 weeks is shown in Figure 1. The CO-NPs revealed a bimodal size distribution, although it showing two peaks, but second peak intensity was very low (under 10\%) and the peak is edge peak distribution. This means is an additional, out of place peak at the edge of the distribution and the data set is an outlier. Nanoparticles are defined as particles with a size between a few nanometers to $1 \mu \mathrm{m}$ (Nakache et al. 1999).

The particle size distribution and PDI of nanocarriers are highly important physical characteristics to be considered. These attributes can affect the bulk properties stability and appearance of the end product (Danaei et al. 2018). Successful encapsulation of flavors and oils should result in an encapsulated powder with minimum surface oil content on the powder particles and maximum retention of the core material, particularly volatiles, inside the particles (Jafari et al. 2008). In this study, PEG nanoparticles were produced by melt dispersion. Because prepared by that technique, so it is a type of matrix. The active in the matrix type of encapsulates might be in the form of tiny droplets or are dispersed at the molecular level throughout the particle (Zuidam and Shimoni 2010).

The qualitative analyses of both pre-, post-formulation, and post-treatment of $\mathrm{CO}$ were performed using GC-MS (Table S1). The results indicated that the main compounds of clove oil were eugenol and trans-Caryophyllene (Table 3 ). This results similar to previous literature with showed eugenol (65.41\%), trans-caryophyllene $(12.6 \%)$ were identified as two major components of clove oil (Moemenbellah-Fard et al. 2020). composition and quantity of essential oils composition vary depending on many factors, like plant health, part of the plant, edaphic factors, climate, and timing of the harvest (Schmidt 2010). Generally, the main components characterize the biological activity of the EOs (Campolo et al. 2018). 
Table 2. Effect of high temperature ( $40^{\circ} \mathrm{C}$ for 6 weeks ) to Z-average size and polydispersity index (PDI) of clove oil nanoparticles (CO-NPs)

\begin{tabular}{lcc}
\hline & NP Size (nm) \pm SD & PDI \pm SD \\
\hline CO-NPs (week 0) & $257 \pm 10 \mathrm{a}$ & $0,352 \pm 0,007 \mathrm{a}$ \\
CO-NPs (week 6) & $173 \pm 3 \mathrm{~b}$ & $0,344 \pm 0,08 \mathrm{a}$ \\
\hline
\end{tabular}

Note: * SD: standard deviation. The number followed by the same letters within the same column are not significantly different at $5 \% \mathrm{t}$-test

Table 3. Chemical composition and percentage content of each component of the CO (clove oil) and CO-NPs (clove oil-nanoparticles) pre- and post-treatment storage at $40^{\circ} \mathrm{C}$ for 6 weeks and UV-box for 5 and 11 days

\begin{tabular}{lcccccccc}
\hline \multirow{2}{*}{ Compounds } & \multicolumn{3}{c}{ Pre-treatment (\%) } & \multicolumn{2}{c}{ Post-heat treatment (\%) } & \multicolumn{3}{c}{ Post-UV treatment } \\
\cline { 2 - 9 } & \multicolumn{3}{c}{ 0 day } & \multicolumn{2}{c}{ 6 weeks } & \multicolumn{2}{c}{ 5 days } & \multicolumn{1}{c}{ 11 days } \\
\cline { 2 - 9 } & CO & CO-NPs & CO & CO-NPs & CO & CO-NPs & CO & CO-NPs \\
\hline Eugenol & 85.39 & 87.52 & 44.5 & 92.61 & 44.1 & 65.72 & 0.23 & 14.4 \\
Trans-caryophyllene & 9.22 & 0.61 & 6.48 & - & - & - & - & - \\
\hline
\end{tabular}

Table 4. Mean values of LC50 and LC90 of CO-NPs on adults of C. ferrugineus

\begin{tabular}{lcc}
\hline Slope & $\mathbf{7 2}$ hours & $\mathbf{1 2 0}$ hours \\
\hline LC50 (\%) (95\% C.I) & $0.734(0.543-0.815) \mathrm{a}$ & $0.676(0.307-0.762) \mathrm{a}$ \\
LC90 (\%) (95\% C.I) & $1.027(0.937-1.157) \mathrm{a}$ & $0,942(0.845-1.090) \mathrm{a}$ \\
\hline
\end{tabular}

*Different lower case letters indicate statistically significant differences among means within each row at a $5 \%$-test. C.I. is a confidence interval.
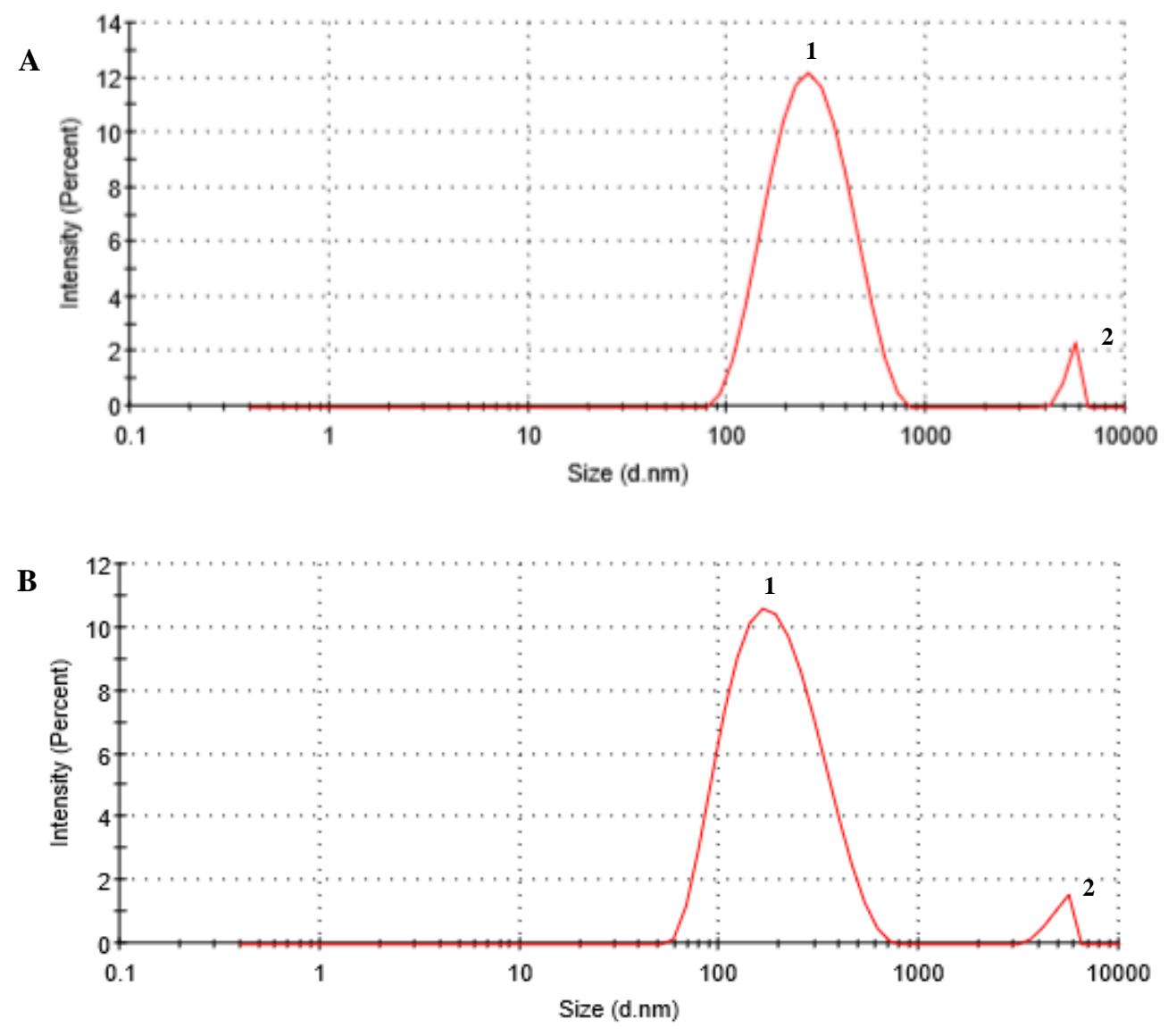

Figure 1. Size distribution of PEG coating nanoparticles loaded with clove essential oil measured by dynamic light scattering at 0 and 6 weeks of storage at $40^{\circ}$ C. A. 0 weeks (Z-average: 268.6; PDI: 0.347; peak size 1: 279.2; \% peak intensity 1: 96.7; peak size 2: 5332; \% peak intensity 1: 3.3). B. 24 weeks of storage (Z-average: 166.6; PDI: 0.358; Peak size 1: 206.9; \% peak intensity 1: 95.6; Peak size 2: 4988; \% peak intensity $2: 3.4$ ) 


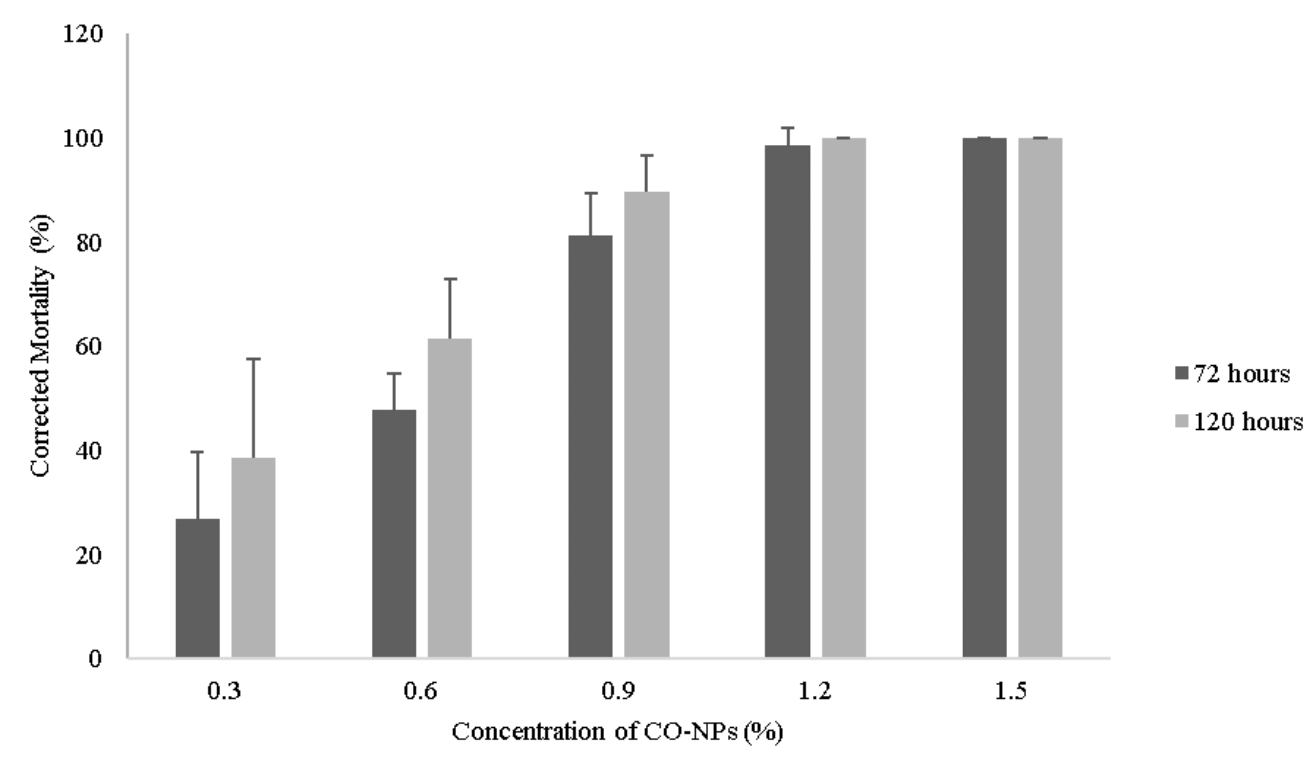

Figure 2. Mortality of C. ferrugineus adults for 24 and 120 hours caused by clove oil-nanoparticles (CO-NPs). The error bars indicate the standard error of the means

Analysis of the results from GC-MS indicates there were no significant chemical variations between $\mathrm{CO}$ and CO-NPs, specifically for eugenol and trans-Caryophyllene, only there were variations of the content of the two major constituents (Table 3). Nanoformulation able to increase the content amount of eugenol, but only around a $2 \%$ increase compared with free clove oil. Otherwise for transCaryophyllene decreased by around 93\%. Besides the volatility and diffusion of the active agent through the wall of the PEG-coated nanocapsule, there are other environmental factors (e.g., temperature, light, and oxygen) that can catalyze reactions, which can cause alteration in the content of the compounds. This decrease is also a function of the susceptibility of the core material to degradation processes, including principal damage, chemical transformations, or polymerization reactions (Turek and Stintzing 2013).

After heating, eugenol content in $\mathrm{CO}$ decreased significantly, which reached a $48 \%$ decrease. While on NPs showed high retention under the same conditions, with around a $6 \%$ increase. For the heating effect on the transCaryophyllene compound, $\mathrm{CO}$ decreased by $30 \%$ and has not been detected in CO-NPs. The reduction in the amount of component is presumably due to oxidation or volatilization. Release characteristics of EOs encapsulate mechanisms depend on the properties of encapsulated EO, the polymer used, physicochemical characteristics of encapsulates (size of the particle and its internal cavity, interaction between EOs and cavity sites), and surrounding environmental conditions (Relative humidity and Temperature) (Jafari et al. 2008). The results further indicate that nanoparticles containing clove essential oil are stable when stored at high temperatures. Encapsulation is a method of providing a protective layer by a coating of single or mixture of polymers over the active ingredient to improve the ingredient's stability, sustainability, and ease out the handling (Vishwakarma et al. 2016). This means this system can decrease volatility and increase the water solubility of essential oil and to transform the oil into a powder (Bilia et al. 2014).

To study the photostability of encapsulated $\mathrm{CO}$ compared with free $\mathrm{CO}$, those samples were placed at the UV lightbox. The photostability of eugenol also was estimated from the eugenol content remaining in GC-MS analysis, after exposure to UV-light. Table 3 also summarizes the photostability of CO-NPs and free clove oil. After $5 \mathrm{~d}, \mathrm{CO}$ and CO-NPs possessed remaining eugenol contents of 44.1 and $65.72 \%$, respectively. While, after 11-day treatment, $\mathrm{CO}$ and CO-NPs possessed remaining eugenol contents of 0.23 and $14.4 \%$, respectively. The higher amount or exhibited slow reduction of eugenol in CO-NPs compared to free clove oil after 5 and 11 days UV-treatment implied that the encapsulation of CO by PEG could improve the photostability of $\mathrm{CO}$.

\section{Residual contact toxicity of CO-NPs}

The $\mathrm{CO}$ and CO-NPs tested in these experiments exhibited different degrees of toxicity towards $C$. ferrugineus adults. NPs decreased the toxicity in the insecticidal activity of $\mathrm{CO}$ because, in the same concentration, $\mathrm{CO}$ appeared to have a very dramatic effect on this insect, killing all the adults at all level concentrations, so the need of lower concentrations to reach linear mortality data or the necessity of shorter exposure time. Differences in their amount of chemical composition may explain the difference in toxicity. Proportions of essential oil compounds can vary and affect their biological activity (Ilboudo et al. 2010). Besides, the reduction in volatile properties is thought to cause reduced toxicity through the respiratory system. However, CO-NPs still had good toxicity by being able to achieve $100 \%$ 
mortality at a concentration of $1,2 \%$ after 120 hours exposure and $1.5 \%$ after 72 and 120 hours exposure (Figure 2). Results show that concentration was significant for the mortality of $C$. ferrugineus after 72 and 120 hours of exposure when treated with CO-NPs (P-value $<0,05)$.

The concentration of the chemicals at which $50 \%$ of the test animals die during a specific period or the concentration lethal to one half of the test population is referred to as median lethal concentration (LC50) or median tolerance limit (Asifa and Chitra 2013). The median lethal concentration (LC50) and LC90 of CO-NPs to $C$. ferrugineus adults are presented in Table 4. The LC50 value for 72 and 120 hours exposure was 0.734 and $0.676 \%$, and there is no significant difference between the two-time exposure. Thus, the longer the exposure time, the higher the toxicity of the CO-NPs, which is indicated by a decrease in the LC50 value at 120 hours exposure.

The main constituent of clove oil was eugenol, where the mode of action is by neurotoxicity. Essential oil compounds exert their activity on insects through neurotoxic effects involving several mechanisms, mainly through GABA, octopamine synapses, and acetylcholinesterase inhibition (Regnault-Roger et al. 2012). Eugenol has been reported to have specific effects on octopamine receptors (neuromodulators) and exerts insecticidal properties through this action (Price and Berry 2006). Interrupting the functioning of octopamine results in the total break down of the nervous system in insects (Tripathi et al. 2009).

Clove oil nanoparticles can be produced using PEG as encapsulated by the melt dispersion method. All of the findings presented here also showed the stability and potential use of CO-NPs in the management of storage pests. For further study, the observed effects of high temperature and UV light on the biological activity of $C$. ferrugineus and other storage pests are needed.

\section{ACKNOWLEDGEMENTS}

The authors gratefully acknowledge LPDP (Indonesia Endowment Fund for Education) for financial support.

\section{REFERENCES}

Abbott WS. 1925. A method for computing the effectiveness of an insecticide. J Econ Entomol 18 (2): 265-267.

Asifa KP, Chitra KC. 2013. Determination of median Lethal Concentration (LC 50 ) and behavioral effects of chlordecone in the cichlid fish, Etroplus maculatus. Intl J Sci Res 4 (3): 1473-1475.

Bandani AR, Kazzazi M, Mehrabadi M. 2009. Purification and characterization of midgut $\alpha$-amylases of Eurygaster integriceps. Entomol Sci 12 (1): 25-32.

Bilia AR, Guccione C, Isacchi B, Righeschi C, Firenzuoli F, Bergonzi MC. 2014. Essential oils loaded in nanosystems: A developing strategy for a successful therapeutic approach. Evid-Based Compl Altern Med 2014: 651593. DOI: 10.1155/2014/651593.

Campolo O, Giunti G, Russo A, Palmeri V, Zappalà L. 2018. Essential oils in stored product insect pest control. J Food Qual 2018: 6906105 DOI: 10.1155/2018/6906105

Chiou WL, Riegelman S. 1971. Pharmaceutical applications of solid dispersion systems. J Pharm Sci 60 (9): 1281-1302.

Danaei M, Dehghankhold M, Ataei S, Hasanzadeh DF, Javanmard R,
Dokhani A, Khorasani, S, Mozafari MR. 2018. Impact of particle size and polydispersity index on the clinical applications of lipidic nanocarrier systems. Pharmaceutics 10 (2): 57. DOI: 10.3390/pharmaceutics10020057.

Forim MR, Costa ES, da Silva MFDGF, Fernandes JB, Mondego JM, Boiça Junior AL. 2013. Development of a new method to prepare nano-/microparticles loaded with extracts of Azadirachta indica, their characterization and use in controlling Plutella xylostella. J Agric Food Chem 61 (38): 9131-9139.

Gasch T. 2014. The use of semiochemicals for stored product protection. Berichte aus dem Julius Kühn-Institut 177: 32.

González JOW, Gutiérrez MM, Ferrero AA, Band BF. 2014. Essential oils nanoformulations for stored-product pest control-Characterization and biological properties. Chemosphere 100: 130-138.

Hazra DK, Karmakar R, Poi R, Bhattacharya S, Mondal S. 2017. Recent advances in pesticide formulations for eco-friendly and sustainable vegetable pest management: A review. Arch Agric Environ Sci 2 (3): 232-237.

Huang B, Chen F, Shen Y, Qian K, Wang Y, Sun C, Zhao X, Cui B, Gao F, Zeng Z, Cui H. 2018. Advances in targeted pesticides with environmentally responsive controlled release by nanotechnology. Nanomaterials 8 (2): 102. DOI: 10.3390/nano8020102.

Ikawati S, Himawan T, Abadi AL, Tarno H. 2020. Fumigant and feeding deterrent activity of essential oils against Cryptolestes ferrugineus (Stephens) (Coleoptera: Laemophloeidae). Biodiversitas 21 (9): 43014308 .

Ilboudo Z, Dabiré LCB, Nébié RCH, Dicko IO, Dugravot S, Cortesero AM, Sanon A. 2010. Biological activity and persistence of four essential oils towards the main pest of stored cowpeas, Callosobruchus maculatus (F.) (Coleoptera: Bruchidae). J Stored Prod Res 46 (2): 124-128.

Isman MB. 2016. Pesticides based on plant essential oils: Phytochemical and practical considerations. Am Chem Soc 2016: 13-26.

Jafari SM, Assadpoor E, He Y, Bhandari B. 2008. Encapsulation efficiency of food flavours and oils during spray drying. Dry Technol 26 (7): 816-835.

Koh PT, Chuah JN, Talekar M, Gorajana A, Garg S. 2013. Formulation development and dissolution rate enhancement of efavirenz by solid dispersion systems. Indian J Pharm Sci 75 (3): 291-301.

Lakušić DV, Ristić MS, Slavkovska VN, Åinžar-Sekulić JB, Lakušić BS. 2012. Environment-related variations of the composition of the essential oils of rosemary (Rosmarinus officinalis L.) in the Balkan Penninsula. Chem Biodivers 9 (7): 1286-1302.

Moemenbellah-Fard MD, Abdollahi A, Ghanbariasad A, Osanloo M. 2020. Antibacterial and leishmanicidal activities of Syzygium aromaticum essential oil versus its major ingredient, eugenol. Flavour Fragr J 35 (5): 534-540.

Nakache E, Poulain N, Candau F, Orecchioni AM, Irache JM. Biopolymer and polymer nanoparticles and their biomedical applications. In: Nalwa HS (ed.). Handbook Ofnanostructured Materials and Nanotechnology. Academic Press, New York.

Nayak MK, Holloway JC, Emery RN, Pavic H, Bartlet J, Collins PJ. 2013. Strong resistance to phosphine in the rusty grain beetle, Cryptolestes ferrugineus (Stephens) (Coleoptera: Laemophloeidae): its characterisation, a rapid assay for diagnosis and its distribution in Australia. Pest Manag Sci 69 (1): 48-53.

Nobbmann U. 2014. Polydispersity-what does it mean for DLS and chromatography? Malvern Instruments. https://www.malvernpanalytical.com/en

Plata-Rueda A, Campos JM, da Silva Rolim G, Martínez LC, Dos Santos MH, Fernandes, FL, Serrão JE, Zanuncio JC. 2018. Terpenoid constituents of cinnamon and clove essential oils cause toxic effects and behavior repellency response on granary weevil, Sitophilus granarius. Ecotoxicol Environ Saf 156: 263-270.

Price DN, Berry MS. 2006. Comparison of effects of octopamine and insecticidal essential oils on activity in the nerve cord, foregut, and dorsal unpaired median neurons of cockroaches. J Insect Physiol 52 (3): 309-319.

Regnault-Roger C, Vincent C, Arnason JT. 2012. Essential oils in insect control: low-risk products in a high-stakes world. Ann Rev Entomol 57: 405-424.

Roy A, Singh SK, Bajpai J, Bajpai AK. 2014. Controlled pesticide release from biodegradable polymers. Open Chem 12 (4): 453-469.

Schmidt E. 2010. Production of essential oils. In: Bas er KH, Buchbauer $G$ (eds.) Handbook of Essential Oils. Science, Technology, and Applications. CRC Press, Boca Raton. 
Tripathi AK, Upadhyay S, Bhuiyan M, Bhattacharya PR. 2009. A review on prospects of essential oils as biopesticide in insect-pest management. J Pharmacog Phytother 1 (5): 52-63.

Turek C, Stintzing FC. 2013. Stability of essential oils: A review. Compr Rev Food Sci. Food Saf 12 (1): 40-53.

Vishwakarma GS. Gautam N, Babu JN, Mittal S, Jaitak V. 2016. Polymeric encapsulates of essential oils and their constituents: a review of preparation techniques, characterization, and sustainable release mechanisms. Polym Rev 56 (4): 668-701.

Yang FL, Li XG, Zhu, F, Lei CL. 2009. Structural characterization of nanoparticles loaded with garlic essential oil and their insecticidal activity against Tribolium castaneum (Herbst) (Coleoptera: Tenebrionidae). J Agric Food Chem 57: 10156-10162.

Zanuncio JC, Mourão SA, Martínez LC. Wilcken CF, Ramalho FS, PlataRueda A, Soares MA, Serrão JE. 2016. Toxic effects of the neem oil (Azadirachta indica) formulation on the stink bug predator, Podisus nigrispinus (Heteroptera: Pentatomidae). Sci Rep 6 (1): 30261. DOI: $10.1038 /$ srep30261.

Zuidam NJ, Shimoni E. 2010. Overview of microencapsulates for use in food products or processes and methods to make them. In: Encapsulation Technologies for Active Food Ingredients and Food Processing. Springer, New York. 
Table S1. Chemical constituents analysis of CO and CO-NPs by Gas Chromatography-Mass Spectrometry (GCMS)

\begin{tabular}{|c|c|c|c|c|c|c|c|c|}
\hline \multirow{3}{*}{ Compounds } & \multirow{2}{*}{\multicolumn{2}{|c|}{$\frac{\text { Pre-treatment }(\%)}{\text { 0 day }}$}} & \multirow{2}{*}{\multicolumn{2}{|c|}{$\begin{array}{c}\text { Post-heat treatment (\%) } \\
6 \text { weeks }\end{array}$}} & \multicolumn{4}{|c|}{ Post-UV treatment } \\
\hline & & & & & \multicolumn{2}{|c|}{5 days } & \multicolumn{2}{|c|}{11 days } \\
\hline & $\mathrm{CO}$ & CO-NPs & CO & CO-NPs & $\mathrm{CO}$ & CO-NPs & $\mathrm{CO}$ & CO-NPs \\
\hline Methyl salicylate & 0.09 & & 0.13 & & & & & \\
\hline Eugenol & 85.39 & 87.52 & 44.5 & 92.61 & 44.1 & 65.72 & 0.23 & 14.4 \\
\hline Copaene & & & 0.2 & & & & & \\
\hline Trans-caryophyllene & 9.22 & 0.61 & 6.48 & - & - & - & - & - \\
\hline Alpha-caryophyllene & 0.82 & & 0.9 & & & & & \\
\hline Eugenol acetate & & & 0.53 & & & & & \\
\hline Caryophyllene oxide & & & 1.44 & & & & & \\
\hline Aromadendrene & 0.33 & & & & & & & \\
\hline Gamma-gurjunenepoxide-(1) & & & 0.15 & & & & & \\
\hline Isoaromadendrene epoxide & & & 0.20 & & & & & \\
\hline Ethyl palmitate & & & 0.33 & & & & & \\
\hline Isoeugenol & & & 2.63 & & & & & \\
\hline Dinonyl phthalate & & & 39.85 & & & & & \\
\hline O-Xylene & & 2.06 & & 1.73 & & 5.88 & & 2.19 \\
\hline Dodecane & & & & 1.43 & & & & 1.08 \\
\hline 2.6-dimethylnonane & & & & 1.31 & & & & \\
\hline 2.2.3-trimethyloxetane & & 2.72 & & & & & & \\
\hline Toluene & & 0.91 & & & & 3.32 & & 1.63 \\
\hline 1.3-dimethylcyclohexane & & 0.82 & & & & 1.33 & & 0.96 \\
\hline 1.2-dimethylcyclohexane & & & & & & 1.08 & & \\
\hline Ethyl cyclohexane & & 0.29 & & & & 1.13 & & 0.98 \\
\hline 1-Ethyl-4-methylcyclohexene & & 0.30 & & & & & & \\
\hline Propylcyclohexane & & 0.38 & & & & 1.02 & & 1.05 \\
\hline Propylbenzene & & 0.29 & & & & 0.67 & & \\
\hline Mesitylene & & 0.89 & & & & & & \\
\hline Decane & & 0.34 & & & & 0.97 & & \\
\hline 4-methyldecane & & 0.28 & & & & & & \\
\hline Decahydronaphthalene & & 0.43 & & & & 1.01 & & \\
\hline Undecane & & 0.33 & & & & 2.75 & & 1.13 \\
\hline 2.6-dimethylnonane & & 0.29 & & & & 0.9 & & \\
\hline 4-methyl-1-undecane & & 00.27 & & & & & & \\
\hline Methylethylacetone & & & & & & 1.49 & & \\
\hline 1-ethoxypentane & & & & & & 6.32 & & 5.13 \\
\hline Cyclohexaneethanol & & & & & & 0.75 & & \\
\hline Heptane. 3-ethyl-5-methyl- & & & & & & 0.77 & & \\
\hline 1.2.3-trimethylbenzene & & & & & & 1.3 & & 0.97 \\
\hline 3.3-dimethyloctane & & & & & & 0.86 & & 0.79 \\
\hline Dioctyl phthalate & & & & & & 0.96 & & \\
\hline 1. 1-diethoxyethane & & & & & 39.94 & & & 61.59 \\
\hline (-)-beta-Elemene & & & & & 0.58 & & & \\
\hline Chloromethyl 6-chloroheptanoate & & & & & 0.89 & & & \\
\hline D-galacto-oct-2-enitol & & & & & 0.56 & & & \\
\hline Cesium trimethylfluoro) aluminate & & & & & 0.68 & & & \\
\hline Methylcyclohexane & & & & & & & & 0.89 \\
\hline 1-isobutoxyethylene & & & & & & & & 0.87 \\
\hline Ethylbenzene & & & & & & & & 1.14 \\
\hline 4.5-dimethyloxazole & & & & & & & & 0.82 \\
\hline Xylene & & & & & & & & 1.21 \\
\hline \{Tris(mesityl-gallium) [gallium(h) & & & & & & & & \\
\hline T-butyl]-tetrakis[t-butylphosphane & & & & & & & & 1.17 \\
\hline Butyl 2.4-dimethyl-2-nitro-4-pentenoate & & & & & & & & \\
\hline 6.6-dimethylundecane & & & & & & & & 0.97 \\
\hline Methyl octanoate & & & & & & & 0.02 & \\
\hline Methyl decanoate & & & & & & & 0.01 & \\
\hline Methyl dodecanoate & & & & & & & 0.07 & \\
\hline Methyl octadecanoate & & & & & & & 0.02 & \\
\hline Unknown constituents & 0.18 & & & & 13.26 & 1.78 & 99.66 & \\
\hline
\end{tabular}

